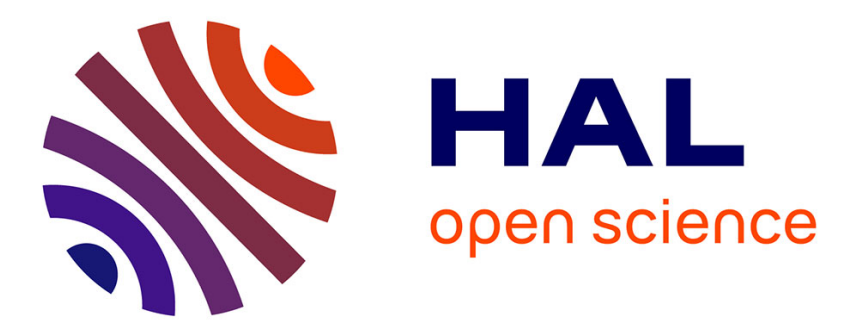

\title{
Feasibility Study of an Adaptive-Pressure Plasma Coating Process-Part 1: Model Description
}

Dmitrii Ivchenko, Gilles Mariaux, Armelle Vardelle, Simon Goutier, Tatiana Itina, Pascal André

\section{- To cite this version:}

Dmitrii Ivchenko, Gilles Mariaux, Armelle Vardelle, Simon Goutier, Tatiana Itina, et al.. Feasibility Study of an Adaptive-Pressure Plasma Coating Process-Part 1: Model Description. Journal of Thermal Spray Technology, 2019, 29, pp.25-37. 10.1007/s11666-019-00948-z . hal-02371163

\section{HAL Id: hal-02371163 https://hal.science/hal-02371163}

Submitted on 22 Sep 2021

HAL is a multi-disciplinary open access archive for the deposit and dissemination of scientific research documents, whether they are published or not. The documents may come from teaching and research institutions in France or abroad, or from public or private research centers.
L'archive ouverte pluridisciplinaire HAL, est destinée au dépôt et à la diffusion de documents scientifiques de niveau recherche, publiés ou non, émanant des établissements d'enseignement et de recherche français ou étrangers, des laboratoires publics ou privés. 


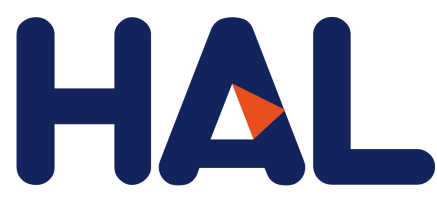

archives-ouvertes

\section{Feasibility Study of an Adaptive-Pressure Plasma Coating Process-Part 1: Model Description}

Dmitrii Ivchenko, Gilles Mariaux, Armelle Vardelle, Simon Goutier, Tatiana Itina, Pascal André

\section{To cite this version:}

Dmitrii Ivchenko, Gilles Mariaux, Armelle Vardelle, Simon Goutier, Tatiana Itina, et al.. Feasibility Study of an Adaptive-Pressure Plasma Coating Process-Part 1: Model Description. Journal of Thermal Spray Technology, ASM International/Springer, 2019, 29, pp.25-37. 10.1007/s11666-01900948-z . hal-02371163

\section{HAL Id: hal-02371163 \\ https://hal.archives-ouvertes.fr/hal-02371163}

Submitted on 22 Sep 2021

HAL is a multi-disciplinary open access archive for the deposit and dissemination of scientific research documents, whether they are published or not. The documents may come from teaching and research institutions in France or abroad, or from public or private research centers.
L'archive ouverte pluridisciplinaire HAL, est destinée au dépôt et à la diffusion de documents scientifiques de niveau recherche, publiés ou non, émanant des établissements d'enseignement et de recherche français ou étrangers, des laboratoires publics ou privés. 


\title{
Feasibility Study of an Adaptive-Pressure Plasma Coating Process-Part 1: Model Description
}

\author{
Dmitrii Ivchenko ${ }^{1} \cdot$ Gilles Mariaux $^{1} \cdot$ Armelle Vardelle $^{1} \cdot$ Simon Goutier $^{1} \cdot$ \\ Tatiana E. Itina ${ }^{2} \cdot$ Pascal André $^{3}$
}

\begin{abstract}
Thermal barrier coatings for gas turbine engines are mainly produced by electron beam physical vapor deposition or atmospheric plasma spray depending on the thermomechanical loading of engine components. This study deals with the numerical design of a two-step thermal plasma-aided physical vapor deposition process capable of efficiently evaporating the coating material processed in the plasma jet and of producing a strain-tolerant coating microstructure from vapor phase condensation. The system involved a high-pressure chamber and a low-pressure chamber connected by an expansion nozzle. The objective was to achieve the highest deposition efficiency for a given plasma specific enthalpy. The numerical simulations based on computational fluid dynamics and direct simulation Monte Carlo models projected the effect of the process geometry and operating conditions on the gas flow fields, powder vaporization efficiency and nucleation/growth phenomena in the gas phase. For a targeted powder feed rate, they allowed to determine the length of the high-
\end{abstract}

This article is an invited paper selected from presentations at the 2019 International Thermal Spray Conference, held on May 26-29, 2019, in Yokohama, Japan, and has been expanded from the original presentation.

Gilles Mariaux

mariaux@ensil.unilim.fr

Dmitrii Ivchenko

dmitrii.ivchenko@etu.unilim.fr

1 University of Limoges, CNRS, The Institute of Research for Ceramics (IRCER), UMR 7315, 87000 Limoges, France

2 Laboratoire Hubert Curien, University of Lyon, UJM-SaintEtienne, CNRS, UMR 5516, 42023 St Etienne, France

3 University of Clermont Auvergne, CNRS, LPC, UMR 6533, 63000 Clermont-Ferrand, France pressure chamber, the diameter of the expansion nozzle and other dimensions of the deposition system. The expansion nozzle that linked the two chambers was the crucial component of the process, and the predictions made it possible to select the geometry and process operating parameters that avoided its clogging and/or melting.

Keywords CFD · DSMC · numerical simulation · nucleation and growth $\cdot$ PS-PVD

\section{Introduction}

In the 1980s, a plasma spray technology called low-pressure plasma spray (LPPS) was proposed to reduce the oxidation of plasma-sprayed metals. It used a deposition chamber filled with an inert atmosphere and held at a pressure of about 5-20 $\mathrm{kPa}(\operatorname{Ref} 1)$.

More recently, a new class of plasma spray processes known as very low-pressure plasma spray (VLPPS) emerged; it was developed on the basis of the low-pressure plasma spraying technique. The first VLPPS process was designed in the 1990s by Eric Muehlberger of Sulzer Metco to produce uniform thin dielectric coatings over large areas of metal sheets. It used a higher electric power input to the plasma torch and lower deposition chamber pressure (5-200 Pa) than that used in LPPS (Ref 2). The decrease in pressure resulted in broader and longer plasma jets (Ref 3 ). This technique initially achieved the deposition of coatings built by the impact of molten droplets, which resulted in broad and uniform yet dense and thin coatings and was called LPPS-TF (TF thin film) by Sulzer Metco AG.

With the development of higher-power plasma spray guns (up to $180 \mathrm{~kW}$ ) (Ref 4) and use of fine feedstock 
powder (primary particle diameter less than $1 \mu \mathrm{m}$ ), the evaporation of a large fraction of the processed particles became possible. The technique was, then, called plasma spray physical vapor deposition (PS-PVD) since the coating was being built from the vapor phase. This technology allowed the fabrication of columnar coatings, similar to the ones produced by electron beam physical vapor deposition (EB-PVD) (Ref 5-9). The low pressure in the deposition chamber caused an increase in the vapor jet length but also width, enabling non-line-of-sight deposition that was not achievable in other PVD processes.

With much lower equipment and operation cost, PSPVD could be an alternative process to EB-PVD. However, several issues reduce the system effectiveness and increase operating expenditures and coating prices:

- Most of the plasma torches used in PS-PVD use high electric power $(180 \mathrm{~kW})$ and plasma-forming gas flow rates (about $100 \mathrm{slm}$ ); they also require frequent part replacement due to intense erosion (electrodes, etc);

- Only very fine particles with specific morphologies (e.g., agglomerated-sintered particles) can be fully evaporated due to the short residence time of the processed particles in the high-pressure region of the process (torch nozzle) and low operating pressure in the deposition chamber;

- Injection of the powder upstream of the torch nozzle exit is used to maximize the particle dwelling time in the hot and dense zone of the plasma jet and so increase the particle evaporation rate. However, the powder internal injection increases the torch complexity and poses a risk of nozzle clogging;

- Even though the internal injection allows increasing the heat flux to particles, the plasma gas velocity inside the torch is high $(2000-6000 \mathrm{~m} / \mathrm{s}$, (Ref 10)), and particle residence time in the part of the jet efficient for particle heating is limited.

In order to address the aforementioned limitations, we propose a two-step thermal plasma-aided physical vapor deposition process (Fig. 1). The first step of the process consists in evaporating the powder in a controlled-atmosphere high-pressure chamber (HPC) designed to increase the powder residence time in the hot and "denser" part of

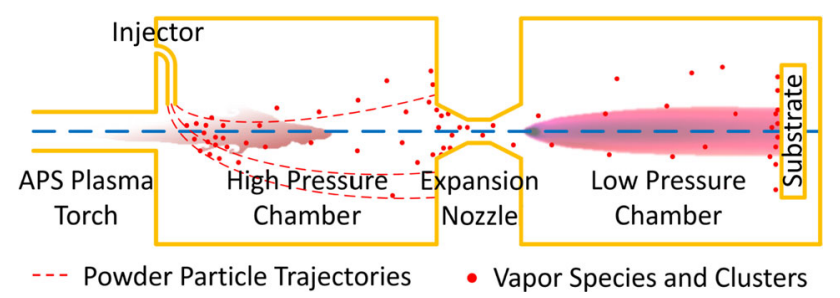

Fig. 1 Schematic of the two-step deposition process the plasma jet. The second step consists in depositing the vapor in a low-pressure chamber (LPC), connected to the first chamber by a supersonic expansion nozzle.

More specifically, this process differs from the PS-PVD processes on the following points:

- Use of a low-power plasma torch (40 kW) with a large diameter nozzle $(10 \mathrm{~mm})$ to achieve a low-velocity plasma jet (Ref 11);

- Injection of the powder in the plasma jet downstream of the nozzle exit;

- Use of a controlled-atmosphere chamber with a pressure close to the atmospheric pressure upstream of the deposition chamber to increase the heat transfer to particles in comparison with the conventional PS-PVD process;

- Selection of argon/hydrogen mixture as plasma-forming gas to provide the required specific enthalpy and heat conductivity for the melting and evaporation of refractory materials (e.g., zirconia) and avoid the use of expensive gases like helium;

- Use of powder with primary particles larger than $1 \mu \mathrm{m}$.

However, the operation of such a system might come up against several issues. For instance, the walls of expansion nozzle connecting the high-pressure and low-pressure chambers could be damaged by the high heat load imposed by the hot gas. In addition, the nozzle could be clogged by residual powder particles, recondensed vapor through the heterogeneous nucleation mechanism, and nanoclusters that have already been formed following the homogeneous nucleation mechanism in the volume of gas. These issues can be avoided, or at least minimized, by a preliminary numerical design that aims to calculate the nozzle geometry and establish the operating window of the process. However, this preliminary numerical design requires a set of numerical models representing the major physical phenomena present in the system.

This study presents the numerical models and simulations developed to assess the geometry and spray parameters of the system. The latter should favor the powder evaporation, ensure a sufficient vapor content near the substrate to get EB-PVD-like coating microstructures and avoid/solve the problems, mentioned above. For zirconia powder and set of torch operating conditions, the simulations predicted the vapor flux from powder evaporation in the high-pressure chamber and the vapor density, cluster concentration and size in the low-pressure chamber. They also projected the clogging of the nozzle by gas nucleation and growth on its wall. 


\section{Modeling Tools}

The simulations performed in this work used the three following models:

Model 1 3D computational fluid dynamics (3D CFD) model of the plasma gas and vapor flow in the high-pressure chamber coupled with a powder-processing model. The 3D model was required to capture the 3D-effects caused by the radial injection of the powder. The model predicted the minimal chamber length required to optimize the vaporization of particles of a given size and the vapor content in the plasma flow. It was implemented in ANSYS Fluent 16.2 CFD software.

Model 2 axisymmetric 2D CFD model of the highpressure chamber and expansion nozzle flow coupled (1way coupling) with a vapor nucleation, nanocluster growth and deposition model (N\&G). This model was used to design the expansion nozzle by estimating its clogging rate. The nucleation and growth model was developed from Nemchinsky's model (Ref 12) and linked to ANSYS Fluent.

Model 3 axisymmetric 2D kinetic model (direct simulation Monte Carlo model, DSMC) of the low-pressure chamber flow, coupled (1-way coupling) with the vapor nucleation and nanocluster growth model (N\&G). This model was used to assess the gas jet characteristics in the low-pressure chamber. The model was implemented in the DSMC code SPARTA (Ref 13, 14).

Axisymmetric models were used because of the azimuthal uniformity of the flows inside the expansion nozzle and downstream from it. Models used time-averaged formulation as transient effects have not been considered in this first step. The domains of application of the three aforementioned numerical models are shown in Fig. 2.

\section{Plasma Flow Under Atmospheric Pressure}

The CFD approach, typically used for continuum flow modeling (Ref 15,16 ), was adopted in the present study. It consisted in solving the Navier-Stokes, energy and species conservation equations for an ideal gas. It was based on the following assumptions:

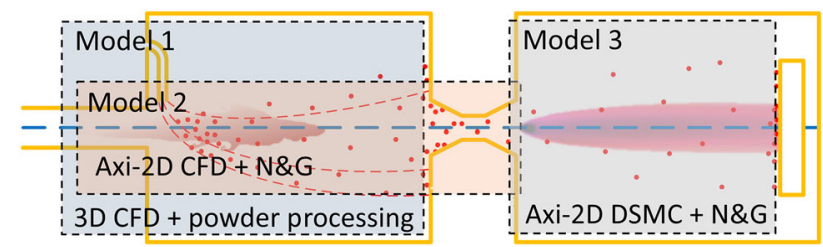

Fig. 2 Schematic of process modeling. Rectangles indicate the domains where the corresponding models were used
- The plasma gas was a continuum medium, which implies that it can be described in terms of temperature, pressure, enthalpy and bulk velocity (the Knudsen number $\mathrm{Kn}$ that characterizes the rarefaction degree is lower than 0.01);

- The gas was in local thermodynamic equilibrium (LTE), which means that some moderate gradients of temperature, density and other gas properties can be present, but they should be low enough so that a gas molecule can have enough time to adopt the temperature of the surrounding medium during its diffusion or convection.

Additional assumptions, specific for thermal plasma modeling, included the following:

- Demixing and chemical reactions between the different gases composing plasma gas, carrier gas and ambient gas were not considered, and their transport and thermodynamic properties were temperature and pressure dependent;

- The gas was a Newtonian fluid, with a linear relation between the stress tensor and velocity gradient;

- The flow was stationary, and time-averaged quantities could adequately represent it;

- The plasma was assumed to be already formed: the plasma-forming gas was already preheated;

- The gas flow was turbulent; the SST k- $\omega$ turbulence model was used to close the set of the flow equations.

These assumptions were experimentally validated under classical atmospheric plasma spray (APS) conditions in Ref 17].

\section{Plasma Flow in the Low Vacuum}

The CFD approach is also typically used for plasma flow modeling under PS-PVD conditions (Ref 18-20). However, it might lead to inaccurate predictions (e.g., underestimation of gradient and broadening of shock waves) for the following reasons:

- The conservation equations assume the fluid to be a continuum medium;

- The linear relations between the stress tensor and velocity gradient (Newton's law of viscosity) and between the thermal heat flux and temperature gradient (Fourier's law), classically used in the conservation equations, become nonlinear in rarefied flows (Ref 21);

- The turbulence models can yield significant errors when applied to supersonic flows (Ref 22).

An alternative is to use a numerical method for solving the Boltzmann equation based on the so-called direct simulation Monte Carlo (DSMC), which has received wide 
recognition in recent years ( $\operatorname{Ref} 23,24)$. It involves the direct simulation of the movement of a statistically representative number of gas molecules. The applicability of DSMC for plasma flow simulations under PS-PVD conditions has been studied by Ivchenko et al. (Ref 25). Their study revealed substantial errors in the CFD predictions due to significant thermal disequilibrium in the oblique and barrel shocks. A detailed description of the DSMC model used in this work can be found elsewhere (Ref 25, 26). Variable soft sphere (VSS) Ar, $\mathrm{H}, \mathrm{H}_{2}$ and hard sphere (HS) $\mathrm{Zr}$ and $\mathrm{O}$ molecules were considered. Flow chemistry was considered by taking into account dissociation and recombination reactions of hydrogen. $\mathrm{ZrO}_{2}$ molecules and reactions between $\mathrm{Zr}$ and $\mathrm{O}$ species between each other and the other molecules were not modeled due to a lack of experimental data. To justify the validity range of this assumption in terms of temperature and pressure of zirconia vapor, we determined the equilibrium vapor composition using the method of minimization of Gibbs free energy (Ref 27).

To calculate the equilibrium vapor composition, 7 chemical species in the gas phase were taken into account: $\mathrm{ZrO}_{2}, \mathrm{ZrO}, \mathrm{O}_{2}, \mathrm{O}, \mathrm{Zr}, \mathrm{Zr}^{+}$and electrons. $\mathrm{ZrO}^{+}$ions were not considered due to their instability. The results of this calculation for $100 \mathrm{~Pa}$ and $10^{5} \mathrm{~Pa}$ shown in Fig. 3 indicate that the dissociation of $\mathrm{ZrO}_{2}$ and $\mathrm{ZrO}$ occurs at a lower temperature when the pressure is lower. Thus, the representation of zirconia vapor as a mixture of gaseous $\mathrm{Zr}$ and $\mathrm{O}$ is valid for temperatures above $4500 \mathrm{~K}$ under $100 \mathrm{~Pa}$. Nevertheless, the validity range can be broadened by large deviations from the chemical equilibrium inside the rarefied flow in the LPC.

The DSMC model has been validated (Ref 25) against the measurements of Selezneva et al (Ref 23) under VLPPS conditions with a $4-\mathrm{kW}$ (net) plasma torch operated with pure $\mathrm{Ar}$ and against the measurements of Mauer et al with a 26-kW(net) plasma torch operated with an $\mathrm{Ar} / \mathrm{H}_{2}$ gas mixture (Ref 28).

\section{Powder Treatment}

A conventional powder-processing model based on the Lagrangian approach was used to calculate the particle trajectories, acceleration, heating and evaporation (Ref 29, 30). The model relied on the following assumptions:

- The particles were considered spherical, isotropic and homogeneous;

- Particle-particle interactions were disregarded as their volume fraction was less than $10 \%$;

- Particle movement was mainly controlled by the drag force exerted by the plasma flow and turbulence that caused their dispersion;

- Heat exchange between particles and gas occurred through convection, and particle heat loss also occurred through radiation;

- Particles were considered as thermally thin, i.e., the temperature was assumed to be constant throughout the particle volume.

The particle processing model was dynamically coupled with the 3D CFD plasma flow model in the high-pressure chamber. The validity of the assumptions was confirmed in the studies of Matthias de Sousa and Pierre Fuzet (Ref 17, 31) for common APS conditions. Additional corrections of the particle drag and heat transfer coefficients were introduced to account for evaporation and rarefaction effects (Ref 32, 33).

\section{Nucleation and Nanocluster Growth}

The calculation of zirconia vapor nucleation and nanocluster growth was based on the kinetic nucleation theory by Girshick (Ref 34) and monodisperse approximation of the growth process by Nemchinsky and Shigeta (Ref 12). To solve these equations, the Lagrangian approach was used. As a result, the zirconia vapor and nanocluster content were evaluated per unit mass of the surrounding gas flow traveling along a streamline.

The process of nanocluster formation shown in Fig. 4 was described by the following stages (Ref 35$)$ :
Fig. 3 Equilibrium compositions of $\mathrm{ZrO}_{2}$ vapor at 1 atm (left) and at $100 \mathrm{~Pa}$ (right) (Ref 27)
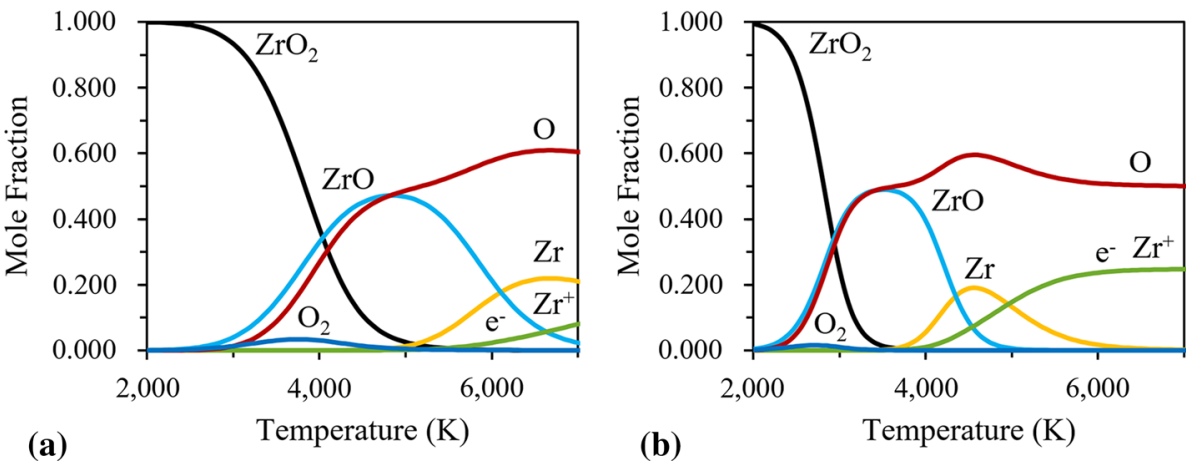


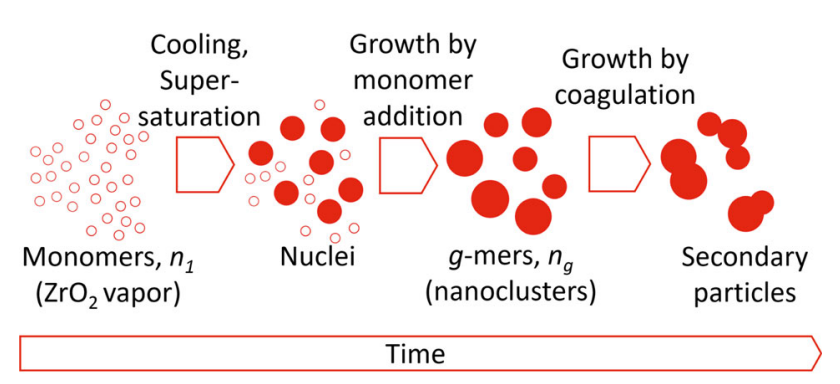

Fig. 4 Schematic of the homogeneous nucleation and growth processes

- Formation of initial stable clusters from zirconia vapor (monomers with the concentration $n_{1}$ ) due to supersaturation associated with vapor cooling;

- Growth of the primary particles ( $g$-mers with the concentration $n_{g}$ where $g$ stands for the number of monomers per one $g$-mer) by condensation of monomers onto the stable clusters;

- Formation of secondary particles by coagulation.

Here, the following assumptions were adopted:

- Under the conditions of the study, the nuclei were only formed from $\mathrm{ZrO}_{2}$ atoms, i.e., the presence of $\mathrm{ZrO}, \mathrm{Zr}$ and $\mathrm{O}$ atoms was neglected according to the equilibrium composition of $\mathrm{ZrO}_{2}$ vapor (Ref 26). This assumption is roughly valid for temperatures lower than $4,000 \mathrm{~K}$ at atmospheric pressure or $3,000 \mathrm{~K}$ at $100 \mathrm{~Pa}$, as it can be seen in Fig. 3;

- The aerosol, formed during the nucleation process, was composed of uniformly sized species, with the size corresponding to the most probable value;

- Unlike in the original formulation, the surrounding gas was assumed to have significant pressure and temperature gradients;

- The secondary particles were deleted from the system immediately after their formation.

In the kinetic nucleation theory developed by Girshick et al. (Ref 34) and built on the foundation of the classical nucleation theory, the formation rate of the stable zirconia clusters (or homogeneous nucleation rate) $J\left(\mathrm{~m}^{-3} \mathrm{~s}^{-1}\right.$ ) was calculated as follows:

$J=v_{1} \sqrt{\frac{2 \sigma}{\pi m_{1}}} n_{s}^{2} S \exp \left(\theta-\frac{4 \theta^{3}}{27 \ln ^{2} S}\right)$,

where $v_{1}\left(\mathrm{~m}^{3}\right)$ is the volume of a monomer, $\sigma$ is the surface tension $(\mathrm{N} / \mathrm{m}), m_{1}$ is the mass of a monomer, $n_{\mathrm{s}}\left(\mathrm{m}^{-3}\right)$ is the equilibrium monomer concentration for saturated vapor, $S$ is the saturation ratio, $S=n_{1} / n_{\mathrm{S}}, n_{1}\left(\mathrm{~m}^{-3}\right)$ is the monomer concentration, $\theta$ is the dimensionless surface energy, $\theta=\sigma S_{1} /\left(k_{\mathrm{B}} T\right), k_{\mathrm{B}}$ is the Boltzmann constant, and $S_{1}\left(\mathrm{~m}^{2}\right)$ is the surface area of a single monomer. The equilibrium monomer concentration was taken from the literature (Ref 36 ) in the form of an exponential regression for temperatures varying from 2,000 to $6,000 \mathrm{~K}$ :

$n_{\mathrm{s}}=10^{(13.312-37421 /(T-273))} /\left(k_{\mathrm{B}} T\right)$

The material data required for the calculations are listed in Table 1 (Ref 37, 38). The critical nanocluster size was given by:

$g^{*}=\left(\frac{2 \theta}{3 \ln S}\right)^{3}$

The processes of nanocluster growth and the formation of secondary particles were described by the following system that includes one algebraic and two differential equations with number densities calculated per unit density to account for gas and vapor pressure variations ( $\operatorname{Ref} 26)$ :

$\left\{\begin{array}{l}\frac{\mathrm{d} n_{1}^{\prime}}{\mathrm{d} l}=-\frac{\mathrm{d} u_{\mathrm{g}}^{\prime}}{\mathrm{d} l}+\frac{\mathrm{d} n_{1, \text { nit }}^{\prime}}{\mathrm{d} l} \\ \frac{\mathrm{d} n_{\mathrm{g}}^{\prime}}{\mathrm{d} l}=C_{1}(S) \frac{J}{\rho v_{1}}-C_{2}(g) \frac{1}{2} \frac{\beta_{\mathrm{gg}}}{v_{1}} n_{g}^{2} \rho \\ \frac{\mathrm{d} u_{\mathrm{g}}^{\prime}}{\mathrm{d} l}=C_{1}(S) \frac{J g^{*}}{\rho v_{1}}+C_{2}(g) \frac{\beta_{1 g}}{v_{l}}\left(n_{1, \text { init }} \prime-u_{\mathrm{g}} \prime-n_{\mathrm{s}}^{\prime}\right) n_{\mathrm{g}}^{\prime} \rho\end{array}\right.$

(Eq Eq4)

where $n_{1}^{\prime}\left(\mathrm{kg}^{-1}\right)$ is the number density of monomers per unit mass of the medium, $n_{1}^{\prime}=n_{1} / \rho, u_{\mathrm{g}}^{\prime}=n_{\mathrm{g}}^{\prime} g\left(\mathrm{~kg}^{-1}\right), \rho$ is the gas density $\left(\mathrm{kg} / \mathrm{m}^{3}\right), l(\mathrm{~m})$ is the distance along streamline, $g$ is the average number of monomers in a particle, $n_{1, \text { init }}^{\prime}$ is the initial monomer number density, derived from the $3 \mathrm{D}$ simulations of the HPC, where $\mathrm{ZrO}_{2}$ vapor molecules were generated by powder particle evaporation, $\beta_{i j}\left(\mathrm{~m}^{3} / \mathrm{s}\right)$ is the collision frequency function between $i$-mers and $j$-mers, $v_{l}$ is the gas speed along the streamline $(\mathrm{m} / \mathrm{s})$, and $n_{\mathrm{s}}^{\prime}$ is the equilibrium monomer concentration (Ref 36). The collision frequency function for free molecular flow is given by the following equation:

$\beta_{i j}=\left(\frac{3}{4 \pi}\right)^{\frac{1}{6}} \sqrt{\frac{6 k_{\mathrm{B}} T v_{1}}{m_{1}}\left(\frac{1}{v_{i}}+\frac{1}{v_{j}}\right)}\left(v_{i}^{\frac{1}{3}}+v_{j}^{\frac{1}{3}}\right)^{2}$

where $v_{i}$ is the volume of an $i$-mer.

Table 1 Material data for the homogeneous nucleation and growth model

\begin{tabular}{ll}
\hline \multicolumn{1}{c}{ Parameter, unit } & \multicolumn{1}{c}{ Value } \\
\hline $\mathrm{ZrO}_{2}$ molecule mass, $\mathrm{kg}$ & $2.04 \times 10^{-25}$ \\
Molecular volume, $\mathrm{m}^{3}$ & $1.81 \times 10^{-29}$ \\
Surface tension of $\mathrm{ZrO}_{2}$ droplet, $\mathrm{N} / \mathrm{m}$ & 1.50 \\
\hline
\end{tabular}


In $\mathrm{Eq} \mathrm{4,} \mathrm{the} \mathrm{first} \mathrm{equation} \mathrm{represents} \mathrm{zirconia} \mathrm{mass}$ conservation. While traveling along the streamline, the zirconia vapor mass increases within an elementary volume due to powder evaporation and decreases due to the formation of nanoclusters. The second equation represents the nanocluster ( $g$-mer) generation by nucleation, which is countered by the nanocluster coagulation that leads to the formation of the secondary particles. The third equation describes the nanocluster growth $-g$-mers are formed with a critical size $g *$ and grow by monomer addition, which is countered by monomer evaporation from the nanocluster surface.

Zero initial content of $g$-mers was assumed at the beginning of a streamline:

$$
\left\{\begin{array}{r}
n_{1}^{\prime}(l=0)=n_{1, \text { init }}^{\prime}(l=0) \\
n_{\mathrm{g}}^{\prime}(l=0)=0 \\
u_{\mathrm{g}}^{\prime}(l=0)=0 .
\end{array}\right.
$$

The conditions along the streamline can vary drastically, making possible the situation when nucleation stops. Moreover, coagulation and evaporation can become dominant under certain conditions, reducing $g$-mer concentration and size to zero. This may lead to non-physical results during the integration process of the system (1). In order to avoid these situations, correction factors $C_{1}$ and $C_{2}$ both equal to unity were introduced. $C_{1}$ nullified the nucleation term if the supersaturation ratio was lower than unity, $C_{2}$ nullified coagulation and monomer collision terms if $g$ was lower than unity.

The nucleation and growth model is in excellent agreement with the original model implemented by Nemchinsky and Shigeta and with the results obtained with the method of moments (Ref 12). However, the model has not been verified for the cases with pressure and temperature gradients, and no experimental verification was possible because of the lack of experimental data.

\section{Deposition of Vapor and Nanoclusters}

The expansion nozzle clogging was assumed to be driven by zirconia vapor and nanocluster deposition. A conservative estimation was made by assuming that the vapor deposition was driven by vapor diffusion toward the nozzle walls and nanocluster deposition, driven by Brownian diffusion and thermophoretic force. Each molecule or particle landing at the nozzle surface was adsorbed. In addition, the reverse processes of vapor desorption and nanocluster detachment were disregarded so that the deposition rates on the wall were overestimated. The overall deposition rate $d(\mathrm{~m} / \mathrm{s})$ was calculated as:
$d=d_{1}+d_{\mathrm{g}}=\frac{m_{1}}{\rho_{\mathrm{ZrO}_{2}}}\left(J_{1}+g J_{g}\right)$

where $d_{1}$ is the monomer deposition rate, $d_{\mathrm{g}}$ is the $g$-mer deposition rate, $m_{1}$ is the mass of a single $\mathrm{ZrO}_{2}$ molecule $(\mathrm{kg}), \rho_{\mathrm{ZrO}_{2}}$ is the density of cubic zirconia $\left(6270 \mathrm{~kg} / \mathrm{m}^{3}\right.$, Ref $36)$, and $J_{1}$ and $J_{\mathrm{g}}$ are monomer and $g$-mer fluxes $\left(\mathrm{m}^{-2} \mathrm{~s}^{-1}\right)$, respectively. The fluxes were evaluated as (Ref 39):

$J_{1}=-D_{\text {vap }} \frac{\partial n_{1}}{\partial n}$

$J_{\mathrm{g}}=\frac{3}{4(1+\pi \alpha / 8)}\left[\frac{n_{\mathrm{g}}^{\prime} \mu}{T} \frac{\partial T}{\partial n}+\frac{8}{r_{1}^{2} g^{2 / 3}} \sqrt{\frac{m_{1, \mathrm{gas}} k_{\mathrm{B}} T}{2 \pi}} \frac{\partial n_{\mathrm{g}}^{\prime}}{\partial n}\right]$

where $D_{\text {vap }}$ is the vapor diffusion coefficient in thermal plasma $\left(\mathrm{m}^{2} / \mathrm{s}\right)$, estimated using the approach presented in Ref 40], $\alpha$ is the accommodation factor, $\alpha=0.8$ (Ref $33,39), n$ is the normal to the nozzle wall, $\mu$ is the surrounding gas viscosity $(\mathrm{kg} / \mathrm{m} / \mathrm{s}), m_{1, \text { gas }}$ is the molecular mass of the gas $(\mathrm{kg})$, and $r_{1}$ is the monomer radius $(\mathrm{m})$.

\section{Coupling the Models}

In different ways of coupling (2-way) or linking (1-way), the models were implemented. 3D CFD and discrete phase models were 2 way-coupled considering source terms in the mass, species, momentum and energy conservation equations to estimate the particle evaporation distance from the injection point and flow vapor content for particle radial injection. The coupling scheme is shown in Fig. 5.

Coupled 3D and 2D axisymmetric CFD models: to simplify the study, the enthalpy source term of the energy equation and $\mathrm{ZrO}_{2}$ species source term of the species

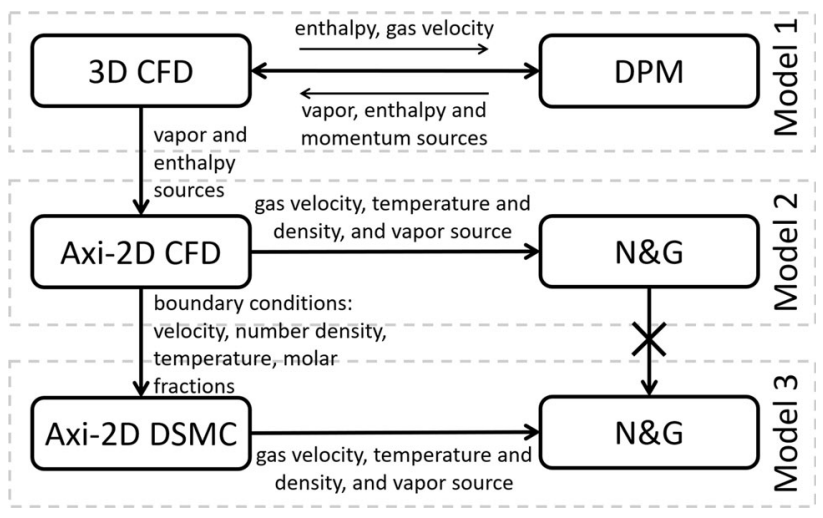

Fig. 5 Schematic of interaction between the models. 1-way coupling is indicated by single-headed arrows, and the 2-way coupling is indicated by a double-headed arrow. Nucleation and growth model linked to the axisymmetric 2D CFD model does not provide boundary conditions to the nucleation and growth model linked to the DSMC simulation 
conservation equation of the 3D CFD models were integrated over the domain and introduced in the corresponding source terms in the axisymmetric CFD model. As the majority of powder evaporation was confined within a small volume near the powder injector outlet, the sources were approximatively localized in a volume located inside the torch nozzle exit in the 2D axisymmetric model. Nonvaporized particles were suppressed from the domain assuming that the vapor can be separated from the particle jet of higher inertia.

Coupled CFD and DSMC models: as the flow in the LPC was supersonic, 1-way coupling was used. The gas and vapor pressure and temperature fields generated by the CFD model at the expansion nozzle outlet were used to calculate the molecule number density fields that were needed to impose the boundary conditions for the DSMC model. The temperatures and bulk velocities of the gas stream were transferred to the DSMC model according to the original CFD mesh and were subsequently reinterpolated to the DSMC mesh.

Linking the axisymmetric 2D CFD and DSMC models with nucleation and growth models: the fluid fields (temperature, density, vapor fraction) extracted along the path lines emitted from the torch nozzle exit in 2D CFD model and from the expansion nozzle exit in DSMC model were used to simulate the nucleation and growth phenomena without affecting the monomer concentration field. Linking the results generated by the nucleation and growth model in coupling with 2D CFD and DSMC models was not required due to the low nucleation rates in the high-pressure chamber.

\section{Approach to Numerical Design}

The determination of the main dimensions of the system was performed in the following order:

(1) Selection of the spray parameters that facilitate the powder vaporization;

(2) Estimation of the HPC length $L_{\mathrm{HPC}}$ to ensure a maximal vapor content using Model 1 (3D CFD model coupled with the powder treatment model);

(3) Calculation of the expansion nozzle dimensions (including its throat radius $r_{\text {nozz }}$ and total length $L_{\text {nozz}}$ ) to ensure the complete evacuation of plasma/vapor gas through the expansion nozzle without wall melting and clogging using Model 2 (axisymmetric 2D CFD model coupled with the nucleation and growth model);

(4) Study of the flow conditions (vapor, cluster size and density) in the LPC to determine the optimal location of the substrate using Model 3 (axisymmetric 2D
DSMC model coupled with the nucleation and growth model).

The effect of the expansion nozzle geometry, mainly convergent and divergent angle, on its wall deposition rate and spray characteristics in the low-pressure chamber will be presented in the upcoming article. Therefore, for the present study, the nozzle length was restricted to $20 \mathrm{~mm}$, which is the minimal part length that can be machined using common machining tools and that limits the cooling of zirconia vapor that could result in vapor condensation on nozzle walls. The nozzle inlet and outlet radii were selected to ensure a smooth change of the nozzle cross section and so avoiding the boundary layer separation and formation of recirculation zones.

\section{Selection of the Operating Conditions}

The plasma torch operating parameters presented in Table 2 were selected to optimize the powder evaporation by increasing the amount of energy transferred to powder particles while using a low-power plasma torch: i) the powder residence time was maximized by using large nozzle diameter, ii) argon and hydrogen mixture with high enthalpy and thermal conductivity were used as plasmaforming gas and, iii) the HPC pressure was maintained close to the atmospheric pressure.

\section{Calculation Domains and Boundary Conditions}

A global schematic of the 3D and axisymmetric 2D CFD models is shown in Fig. 6. Boundary conditions on the torch nozzle inlet were set by imposing the mass flow rate $\left(\mathrm{d} m / \mathrm{d} t=1.08 \times 10^{-3} \mathrm{~kg} / \mathrm{s}\right)$ and temperature $T=13,820 \mathrm{~K}$ according to the following balance: $P_{\text {elec }}=V \times I=h(T) \times \mathrm{d} m / \mathrm{d} t$, where $V$ is the arc voltage, $I$ is the arc current, and $h$ is the average specific enthalpy that corresponds to the average nozzle inlet temperature $T$ at atmospheric pressure. The average temperature of the torch nozzle wall was set to $4100 \mathrm{~K}$ so as to cool down the

Table 2 Torch operating parameters

\begin{tabular}{ll}
\hline \multicolumn{1}{c}{ Parameter } & \multicolumn{1}{c}{ Value } \\
\hline Plasma gas flow rate, slm & $40(\mathrm{Ar}) / 10\left(\mathrm{H}_{2}\right)$ \\
Torch nozzle exit diameter, $\mathrm{mm}$ & 10 \\
Arc current, A & 600 \\
Electric power, $\mathrm{kW}$ & 38.1 \\
Torch efficiency, \% & 45.9 \\
HPC pressure, atm & 1 \\
Powder feed rate, g/min & 5 \\
\hline
\end{tabular}




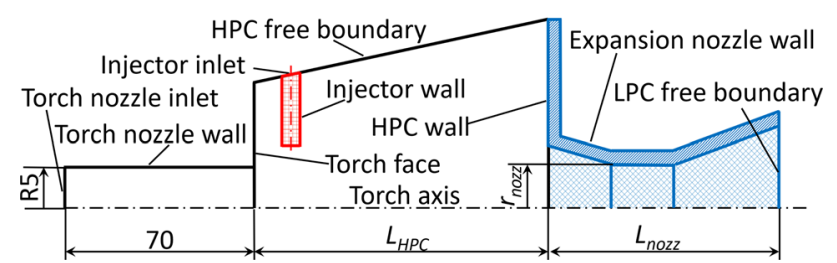

Fig. 6 Schematic of the geometries used in the CFD models. 3D CFD model did not include the expansion nozzle (blue, diamond pattern for the nozzle inside, diagonal pattern for the wall coating), and axisymmetric 2D CFD model did not include the injector (red, grid pattern) (Color figure online)

flow according to the actual torch efficiency and get realistic radial flow profiles.

The HPC and expansion nozzle walls were, in fact, protected with a yttria-stabilized zirconia coating, 200- $\mu \mathrm{m}$ thick to account for the possible deposition of zirconia vapor or clusters, protect the copper expansion nozzle from melting and slow down the clogging process by increasing the maximum acceptable temperature of the wall. Thus, the so-called "thin wall" boundary condition was imposed: the copper wall temperature was set to be 100 degrees lower than the copper melting temperature $\left(T_{\text {melt, } \mathrm{Cu}}=1,358 \mathrm{~K}\right)$, and an additional thermal resistance of the thin copper layer was computed and accounted for during simulations by solving a 1D steady-state heat conduction equation.

Only a part of the HPC in the proximity of the torch axis was included into the calculation domain. Thus, the domain was limited by free boundaries with the imposed pressure of one atmosphere. The domain extended to the expansion nozzle exit; the LPC was not included into the domain and was represented by a free boundary with the LPC pressure held at $100 \mathrm{~Pa}$.

\section{Results and Discussion}

\section{Estimation of the HPC Length}

The initial length of the high-pressure chamber $L_{\mathrm{HPC}}$ was set at $12 \mathrm{~cm}$. Three $\mathrm{ZrO}_{2}$ powders with particles 1,5 and $10 \mu \mathrm{m}$, respectively, were injected in the plasma jet. The $1-\mu \mathrm{m}$ particle size was considered to represent the primary particle size of typical PS-PVD powders (Ref 10), and the 5- and $10-\mu \mathrm{m}$ particles were considered to explore the possibility of the use of coarser particles. The powder injection took into account the particle-particle and wallparticle collisions by introducing a random scatter of particle velocities around the most probable direction along the injector axis (Ref 41) as well as turbulent dispersion. The resulting gas mixture temperature field is shown in Fig. 7 , and the particle trajectories for $1-\mu \mathrm{m}$ particles are shown in Fig. 8.

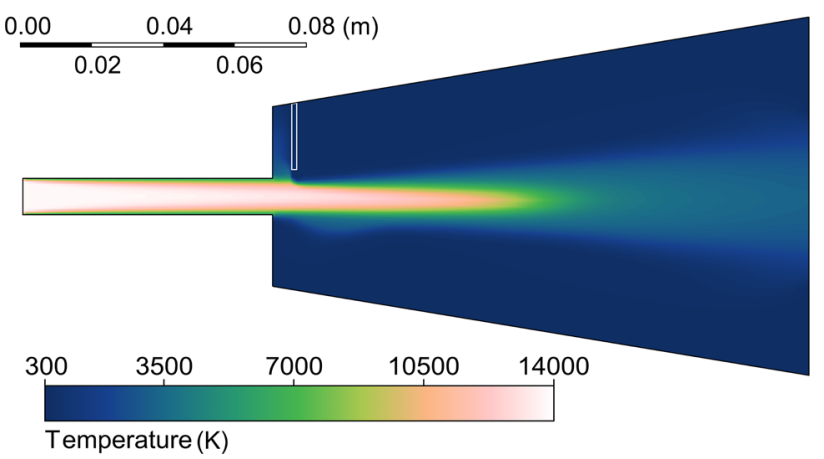

Fig. 7 Gas mixture temperature field in the symmetry plane of the HPC

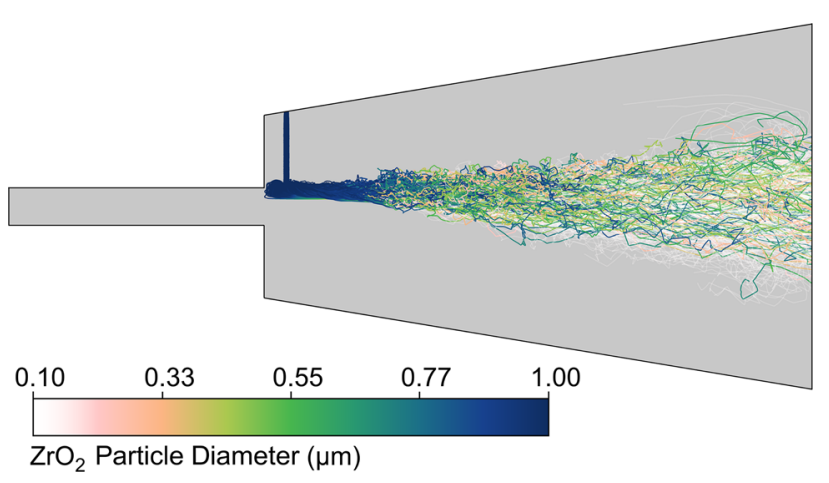

Fig. $81-\mu \mathrm{m}$ particle trajectories. The color scale represents the particle diameter $(\mu \mathrm{m})$ (Color figure online)

The diameter evolution of particles along their trajectories for ten 1- $\mu \mathrm{m}$ particles is represented in Fig. 9. The resulting evaporation degrees of the zirconia powders and corresponding distances from the torch nozzle outlet (along the torch axis) are given in Table 3. The table contains values averaged over a large number of particles so that $95 \%$ of particles would stop evaporation at the calculated distance.

The simulations revealed that the finer particles could reach a very high evaporation degree. However, the complete evaporation was not achieved because of a significant

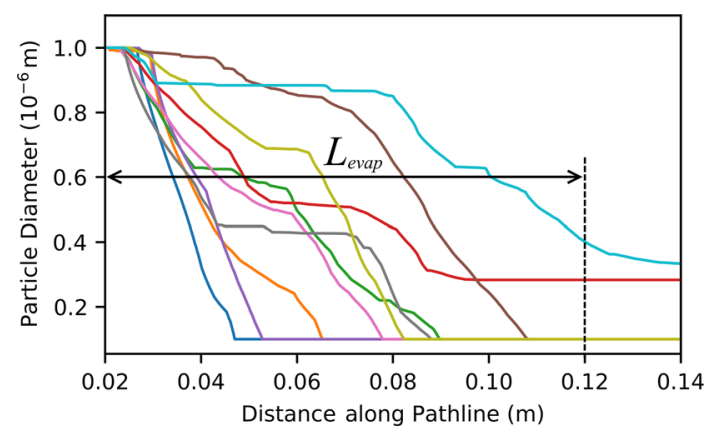

Fig. 9 Evolution of particle diameters along particle trajectories. The plots start at $0.02 \mathrm{~m}-\mathrm{a}$ location that approximately corresponds to the location of the injector outlet 
Table 3 Evaporation degree and evaporation distance for various particle sizes

\begin{tabular}{llll}
\hline Particle diameter $d_{\mathrm{p}}, \mu \mathrm{m}$ & 1 & 5 & 10 \\
Evaporation degree, wt.\% & 72 & 66 & 61 \\
Evaporation distance $L_{\text {evap }}, \mathrm{cm}$ & 10.3 & 8.3 & 7.9 \\
\hline
\end{tabular}

Knudsen effect (Ref 32) that lowered the heat flux to particles. Other reasons were the turbulent dispersion of particles that was driving particles away from the jet and deflection effect apparent for fine particles with low inertia, as shown in Figs. 8 and 9. Table 3 shows that for larger particles of 5 or $10 \mu \mathrm{m}$, the evaporation degree is only slightly lower and that evaporation distances are shorter than for $1 \mu \mathrm{m}$ ones due to lower rarefaction effect.

Thus, since the system was supposed to have the capacity of processing powders of various sizes, the length of the high-pressure chamber $L_{\mathrm{HPC}}$ was set to be $10 \mathrm{~cm}$.

\section{Expansion Nozzle Design}

The initial expansion nozzle radius has been estimated using the isentropic approach, assuming the absence of shockwaves and the inviscid flow inside the nozzle:

$r_{\text {nozz }}^{2}=\frac{(\mathrm{d} m / \mathrm{d} t)_{\mathrm{nozz}}}{\pi}\left(\gamma p_{0} \rho_{0}\right)^{-\frac{1}{2}}\left(\frac{2}{1+\gamma}\right)^{-\frac{1+\gamma}{2(\gamma-1)}}$

where $(\mathrm{d} m / \mathrm{d} t)_{\text {nozz }}$ is the target mass flow rate through the nozzle, $p_{0}$ and $\rho_{0}$ are the gas static pressure and density, respectively, at the nozzle inlet, located at $L_{\mathrm{HPC}}=10 \mathrm{~cm}$ from the torch nozzle outlet, and $\gamma=1.17$ is the adiabatic ratio. These values were derived from the preceding $3 \mathrm{D}$ CFD calculation. Gas properties were taken at $4000 \mathrm{~K}-$ the average temperature in the circular region $3.5 \mathrm{~mm}$ in radius located at $L_{\mathrm{HPC}}$. The target mass flow rate $(1.29 \mathrm{~g} / \mathrm{s})$ comprised plasma gas, carrier gas and zirconia vapor flow rates $(0.1 \mathrm{~g} / \mathrm{s})$ to maintain one atmosphere in the highpressure chamber. The resulting expansion nozzle throat radius $r_{\text {nozz }}$ was estimated to be $2.6 \mathrm{~mm}$.

Next, the nozzle radius calculations were refined with the axisymmetric 2D simulation by accounting for viscous forces and verifying that the heat brought by the plasma jet does not melt the expansion nozzle and HPC walls for the selected HPC length. Due to axisymmetric nature of the simulation, 3D fields of zirconia vapor and enthalpy sources have been converted to axisymmetric 2D source field and moved close to the torch nozzle outlet as shown in Fig. 10. The final throat radius was estimated to be $2.7 \mathrm{~mm}$. Figure 11 shows the predicted coating temperature along the nozzle exterior surface. The highest temperature $(2,887 \mathrm{~K})$ was reached in a small region around

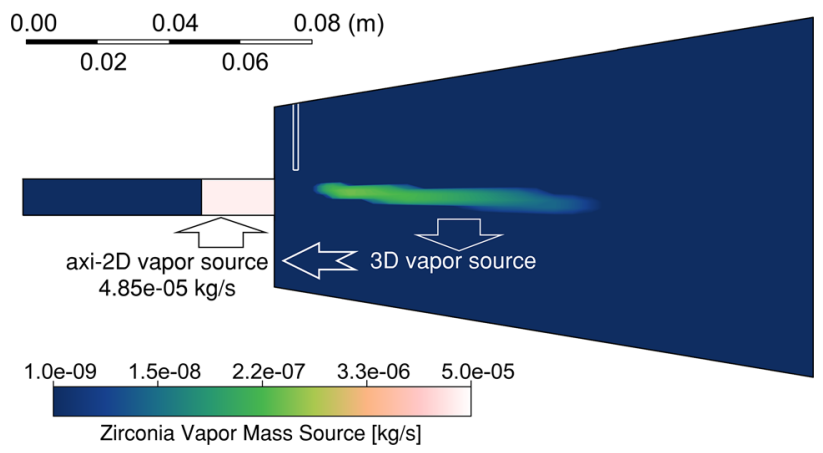

Fig. 10 3D field of zirconia sources and corresponding 2D axisymmetric zirconia source

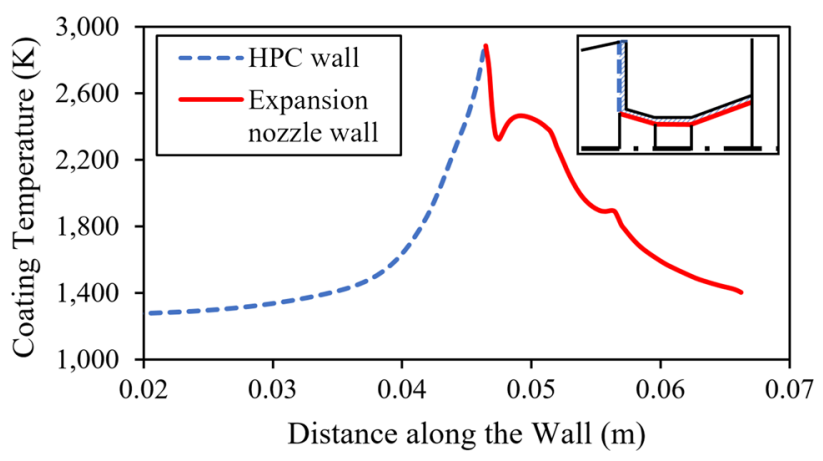

Fig. 11 Maximal temperature of zirconia coating along the walls of HPC and expansion nozzle (blue dashed line-the temperature of at the HPC wall-coated surface, red line-the temperature of the expansion nozzle wall-coated surface) (Color figure online)

the nozzle inlet, but remained lower than zirconia melting

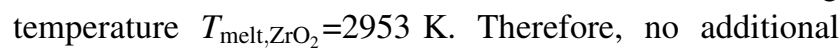
refinement of the high-pressure chamber length was required and it was set to $L_{\mathrm{HPC}}=10 \mathrm{~cm}$.

Finally, the nucleation and growth model was used to estimate the nozzle clogging rates. The projected clogging rates include the contributions of vapor (1-mers) and nuclei ( $g$-mers); they are shown in Fig. 12. Negative monomer or $g$-mer deposition rates signify that the flux direction is toward the nozzle axis. No deposition occurred in the convergent part. The vapor was driven toward the axis by

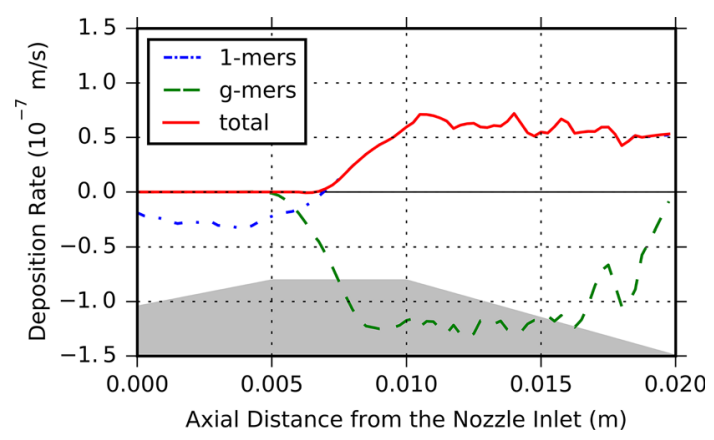

Fig. 12 Expansion nozzle clogging rates 
diffusion forces, since the vapor number density decreased in the direction normal to the wall, while the $g$-mers were simply not present in this part.

In the middle of the cylindrical part, the nucleation consumed part of the vapor and diffusion started driving monomers toward the wall. The recently formed nuclei with a maximal concentration near the wall diffused toward the nozzle axis. The thermophoretic forces that act in the opposite direction were negligible. Thus, the nozzle clogging was only caused by the monomer adsorption.

To illustrate the potential lifetime of the expansion nozzle, a clogging time, defined as the ratio between the critical radius reduction (that was assumed around $\sim 1$ $\mathrm{mm}$ ) and average clogging rate, was determined for the cylindrical part extending from 5 to $10 \mathrm{~mm}$ along the nozzle axis (Fig. 12) and divergent part (from 10 to $20 \mathrm{~mm}$ ) of the nozzle. The resulting values were 14 and $7 \mathrm{~h}$, respectively. Hence, it was shown that despite vapordriven clogging, the proposed system is feasible, capable of operation for at least 7 hours. It should be noted that the considered assumptions for vapor and $g$-mer deposition led to the underestimation of this lifetime. The critical radius reduction was chosen with respect to the characteristic scale of the nozzle throat. This value will be updated based on the maximally allowed deviations of vapor jet parameters from their nominal values once these deviations will be formulated on the subsequent design stages. A study to determine the optimal conditions that minimize nozzle clogging has been performed and will be presented in a future article.

\section{LPC Flow and Its Composition}

DSMC simulations of the gas flow in the LPC were used to calculate the expanding flow structure and composition (vapor fraction, cluster density and size) and, thus, estimate the possible location for the substrate. The DSMC domain started at the expansion nozzle outlet as shown in Fig. 13; it used the axisymmetric 2D CFD simulation results as inlet boundary conditions (temperature, number density, velocity and molar fraction profiles). The substrate was not taken into consideration in the numerical simulations.

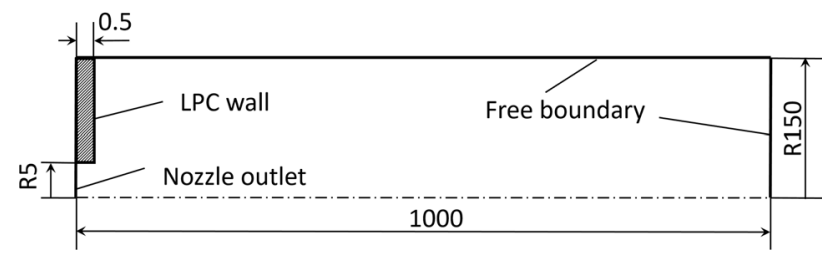

Fig. 13 Axisymmetric 2D DSMC model of the low-pressure chamber (dimensions in $\mathrm{mm}$ )
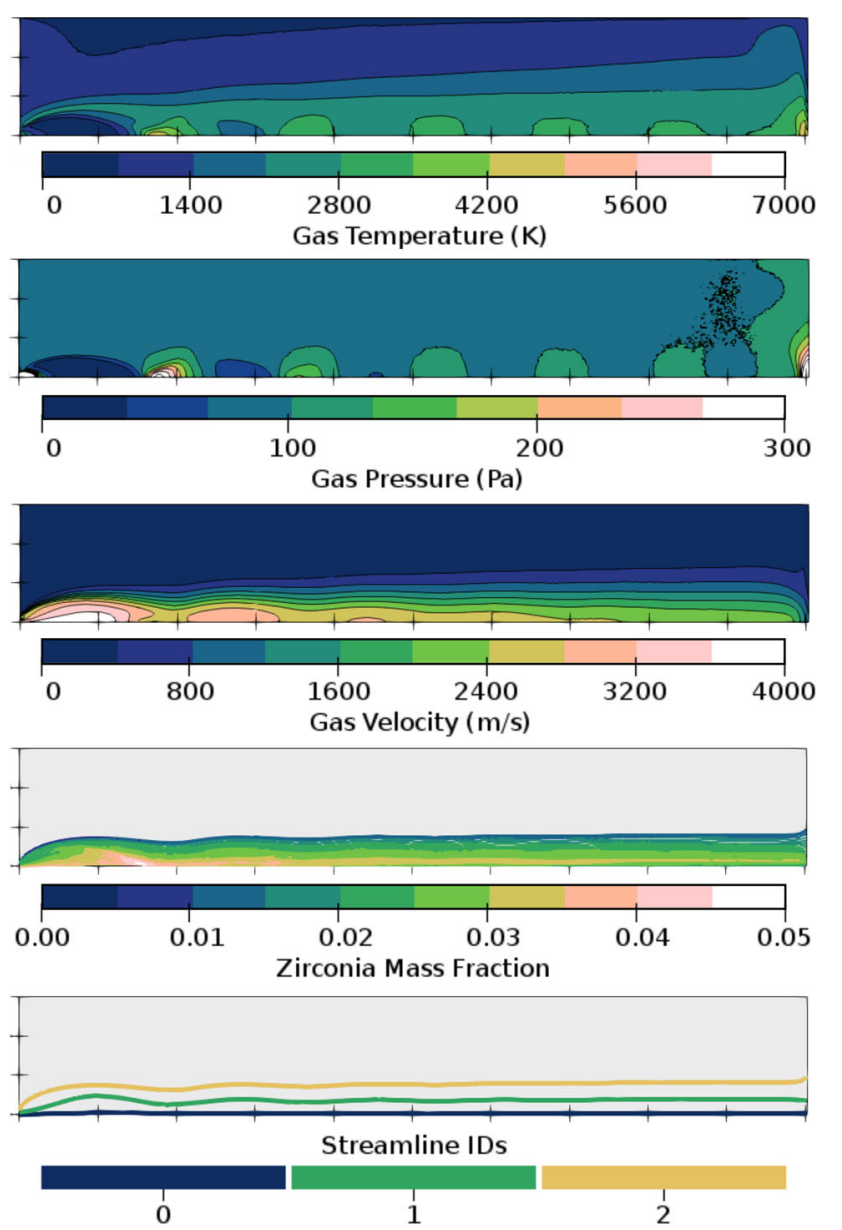

Fig. 14 Results of the axisymmetric 2D DSMC simulations. The last graph shows three different streamlines used in the nucleation and growth calculations

The resulting flow fields of the gas jet are shown in Fig. 14. The supersonic under-expanded flow contained several $(\sim 4)$ normal shock waves (Mach disks) with temperature varying from 300 to $6000 \mathrm{~K}$. The downstream fields were affected by setting zero velocity boundary condition on the right free boundary that led to a significant temperature increase near it. However, the boundary was still considered as open since molecules were able to enter or leave the domain through it to preserve the target molecule number density. The jet core temperature decreased slowly and ranged between 2,800 and 3,500 K throughout the domain. The amplitude of the static pressure fluctuations that followed the expansion, gradually decreased from $30-300 \mathrm{~Pa}$ to $100-130 \mathrm{~Pa}$. The boundary condition used on the right downstream boundary led to an increase in pressure in a small near-boundary area up to $300 \mathrm{~Pa}$. The jet radius, defined as the radius of the vapor plume, stayed around $4 \mathrm{~cm}$ throughout the domain. In the jet core, the gas velocity was maintained around $2000 \mathrm{~m} / \mathrm{s}$. The zirconia mass fraction deduced from the zirconium and 


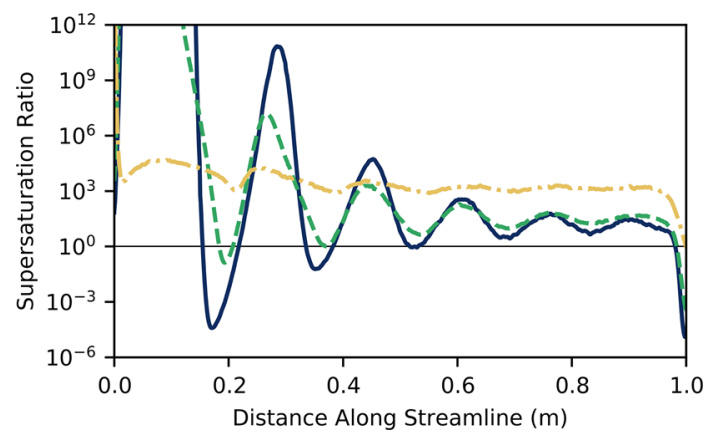

Fig. 15 Supersaturation ratios along the streamlines shown in Fig. 14

oxygen fractions ranged between 2 and $4 \%$ in the jet core and was negligible outside of it. The heavy zirconium molecules did not scatter far from the jet core preserving their initial trajectories along the jet axis.

The nucleation and growth model was applied along the three streamlines shown in Fig. 14. Figure 15 reveals that the supersaturation ratio in the jet periodically exceeded unity, indicating periods of nucleation and nanocluster evaporation along the streamlines. Even though nucleation and growth processes took place during the initial flow expansion and between the shock diamonds, they did not lead to the formation of any substantial number of nanoclusters because of the high degree of rarefaction in the concerned regions. This result indicates that the majority of nanoclusters would be formed in the boundary layer of the substrate resulting in the formation of films composed of both zirconia molecules and nanoclusters. Since the majority of the zirconia powder $(>60 \%)$ was evaporated and transferred to the substrate as a focused vapor jet, according to the PS-PVD structure zone model (SZM) proposed by Mauer et al. (Ref 42), a sufficient impingement rate could be reached and fine columnar coating microstructure should be expected. To avoid the substrate interaction with the most intense shockwaves that can affect the radial uniformity of the coating, the substrate should be placed at any location farther than $50 \mathrm{~cm}$ from the LPC inlet. The effect of the expansion nozzle geometry on the spray characteristics in the low-pressure chamber will be presented in the upcoming article.

\section{System Operation}

The use of time-averaged formulation of numerical models left an important question of achieving operating conditions and maintaining the dynamic balance of pressure beyond the scope of the study. The HPC will be equipped with an atmospheric pump, whereas a vacuum one will be connected to the LPC. Both pumps will be speed-controlled to maintain pressures at their setpoint values using feedback loops. System start-up and operation should be performed in the following stages:

(1) Evacuation of air to reach the nominal LPC pressure.

(2) Switching on the torch (flow only) to reach HPC pressure. LPC pressure is maintained at its setpoint by controlling its pumping speed.

(3) Torch ignition and activation of HPC pump to maintain HPC pressure at its setpoint when HPC pressure is reached.

(4) Activation of carrier gas and powder supply. The pumps regulation loop should be able to control HPC and LPC pressures even when the powder carrier gas flow rate and powder evaporation will proceed.

In addition, after a few hours of operation, clogging would decrease the maximum flow rate through the expansion nozzle. Two ways are then possible to control the HPC pressure: extracting the excess flow with the HPC pump or stopping the latter and controlling the plasmaforming gas flow rate by using pressure feedback loop.

\section{Conclusions}

The preliminary design of a two-step vapor deposition process has been performed by using numerical simulations. CFD and DSMC models have been used to predict the time-averaged thermal plasma/vapor flow fields. These models have been coupled with models describing the powder processing, vapor nucleation and growth and deposition on the walls of the expansion nozzle. The objective was to assess the preliminary geometry of the system.

The results show that the system could evaporate up to 70 wt.\% of the zirconia injected powder and use coarser powders, unlike common PS-PVD systems. However, the presence of residual solid particles or droplets can affect the system operation, and an inertia-based filtering method might be needed.

The nozzle clogging rates predicted by the nucleation and growth model indicate that the minimal operating time of the system has the order of magnitude of hours. The efficient vapor generation can lead to high impingent rates, which favor the generation of finely structured columnar coatings, according to the structure zone model (Ref 42).

This article has demonstrated that the numerical modeling is particularly promising in the design of an adaptivepressure plasma coating process. We have demonstrated the approach chosen for the system design and justified the selection of the operating conditions and high-pressure chamber length (bullet points (1), (2) and, partially, (3) listed in "Approach to Numerical Design" section). The second part of this study will be devoted to the use of the 
aforementioned numerical models for expansion nozzle design and optimization (bullet points (3) and (4) listed in "Approach to Numerical Design" section).

Acknowledgments The authors would like to thank the Région Limousin (later merged into the Région Nouvelle-Aquitaine) for providing financial support.

\section{References}

1. M.F. Smith, A.C. Hall, J.D. Fleetwood, and P. Meyer, Very Low Pressure Plasma Spray-A Review of an Emerging Technology in the Thermal Spray Community, Coatings, 2011, 1(2), p 117132

2. E. Muehlberger, Method of forming uniform thin coatings on large substrates, US, US5853815A, 1998

3. G. Mauer, A. Hospach, and R. Vaßen, Process Development and Coating Characteristics of Plasma Spray-PVD, Surf. Coat. Technol., 2013, 220, p 219-224

4. K. von Niessen, M. Gindrat, and A. Refke, Vapor Phase Deposition Using Plasma Spray-PVDTM, J. Therm. Spray Technol., 2009, 19(1-2), p 502-509

5. K. von Niessen and M. Gindrat, Plasma Spray-PVD: A New Thermal Spray Process to Deposit Out of the Vapor Phase, $J$. Therm. Spray Technol., 2011, 20(4), p 736-743

6. B.J. Harder, D. Zhu, M.P. Schmitt, and D.E. Wolfe, Microstructural Effects and Properties of Non-line-of-Sight Coating Processing via Plasma Spray-Physical Vapor Deposition, J. Therm. Spray Technol., 2017, 26(6), p 1052-1061

7. E. Bakan and R. Vaßen, Ceramic Top Coats of Plasma-Sprayed Thermal Barrier Coatings: Materials, Processes, and Properties, $J$. Therm. Spray Technol., 2017, 26(6), p 992-1010

8. A. Anwaar, L. Wei, Q. Guo, B. Zhang, and H. Guo, Novel Prospects for Plasma Spray-Physical Vapor Deposition of Columnar Thermal Barrier Coatings, J. Therm. Spray. Technol., 2017, 26(8), p 1810-1822

9. W. He, G. Mauer, M. Gindrat, R. Wäger, and R. Vaßen, Investigations on the Nature of Ceramic Deposits in Plasma SprayPhysical Vapor Deposition, J. Therm. Spray Technol., 2016, 26(1-2), p 83-92

10. G. Mauer, Plasma Characteristics and Plasma-Feedstock Interaction Under PS-PVD Process Conditions, Plasma Chem. Plasma Process., 2014, 34(5), p 1171-1186

11. Q.-Y. Chen, X.-Z. Peng, G.-J. Yang, C.-X. Li, and C.-J. Li, Characterization of Plasma Jet in Plasma Spray-Physical Vapor Deposition of YSZ Using a $<80 \mathrm{~kW}$ Shrouded Torch Based on Optical Emission Spectroscopy, J. Therm. Spray. Technol., 2015, 24(6), p 1038-1045

12. V.A. Nemchinsky and M. Shigeta, Simple Equations to Describe Aerosol Growth, Modell. Simul. Mater. Sci. Eng., 2012, 20(4), p 045017

13. M.A. Gallis, J.R. Torczynski, S.J. Plimpton, D.J. Rader, and T. Koehle, Direct Simulation Monte Carlo: The Quest for Speed, Proceedings of the 29th Rarefied Gas Dynamics (RGD) Symposium, J. Fan, Ed., July 13-18, 2014 (Xi'an, China), AIP Publishing, 2014, p 27-36

14. SPARTA Direct Simulation Monte Carlo Simulator, https:// sparta.sandia.gov. Accessed 7 Jul 2018

15. P.C. Huang, J. Hebeylein, and E. Pfender, A two-fluid model of turbulence for a thermal plasma jet, Plasma Chem. Plasma Process., 1995, 15(1), p 25-46

16. K. Bobzin, M. Öte, M. A. Knoch, I. Alkhasli, U. Reisgen, O. Mokrov, and O. Lisnyi, Simulation of the Particle Melting
Degree in Air Plasma Spraying, J. Phys.: Conf. Ser., 2017, 825, p 012002

17. M. De Sousa, "Contribution to solar-grade oxidized silicon waste purification using a thermal plasma based process," Ph.D. Thesis, Université de Limoges, 2014 (in French)

18. B. Vautherin, M.-P. Planche, R. Bolot, A. Quet, L. Bianchi, and G. Montavon, Vapors and Droplets Mixture Deposition od Metallic Coatings by Very Low Pressure Plasma Spraying, $J$. Therm. Spray Technol., 2014, 23(4), p 596-608

19. B. Jodoin, M. Gindrat, J.-L. Dorier, C. Hollenstein, M. Loch, and G. Barbezat, Modelling and Diagnostics of a Supersonic DC Plasma Jet Expanding at Low Pressure, International Thermal Spray Conference, E. Lugscheider and C.C. Berndt, Ed., March 4-6, 2002 (Essen, Germany), DVS Deutscher Verband für Schweißen, 2002, p 716-720

20. M.-J. Liu, K.-J. Zhang, Q. Zhang, M. Zhang, G.-J. Yang, C.-X. $\mathrm{Li}$, and C.-J. Li, Thermodynamic conditions for cluster formation in supersaturated boundary layer during plasma spray-physical vapor deposition, Appl. Surf. Sci., 2019, 441, p 950-959

21. S. Chapman, T.G. Cowling, and D. Burnett, The Mathematical Theory of Non-uniform Gases: An Account of the Kinetic Theory of Viscosity, Thermal Conduction and Diffusion in Gases, Cambridge University Press, 1990

22. K. Sinha, K. Mahesh, and G.V. Candler, Modeling shock unsteadiness in shock/turbulence interaction, Phys. Fluids, 2003, 15(8), p 2290-2297

23. S.E. Selezneva, M.I. Boulos, M.C.M. van de Sanden, R. Engeln, and D.C. Schram, Stationary supersonic plasma expansion: continuum fluid mechanics versus direct simulation Monte Carlo method, J. Phys. D: Appl. Phys., 2002, 35(12), p 1362-1372

24. T.M. Rodgers, H. Zhao, and H.N.G. Wadley, Vapor deposition on doublet airfoil substrates: Coating thickness control, J. Vac. Sci. Technol., A, 2015, 33(6), p 061509

25. D. Ivchenko, T. Zhang, G. Mariaux, A. Vardelle, S. Goutier, and T.E. Itina, On the Validity of Continuum Computational Fluid Dynamics Approach Under Very Low-Pressure Plasma Spray Conditions, J. Therm. Spray Technol., 2017, 27(1-2), p 3-13

26. D. Ivchenko, "Modeling and design of a physical vapor deposition process assisted by thermal plasma (PS-PVD)," Ph.D. Thesis, Université de Limoges, 2018

27. P. André, M. Abbaoui, A. Augeard, P. Desprez, and T. Singo, Study of Condensed Phases, of Vaporization Temperatures of Aluminum Oxide and Aluminum, of Sublimation Temperature of Aluminum Nitride and Composition in an Air Aluminum Plasma, Plasma Chem. Plasma Process., 2016, 36(4), p 1161-1175

28. G. Mauer, D. Ivchenko, G. Mariaux, A. Vardelle, S. Goutier, T. Itina, C. Zhao, and R. Vassen, "Plasma spraying at very low pressure (VLPPS): Model development and experimental validation beyond continuum conditions," presented at the 15th International High-Tech Plasma Processes Conference (HTPP15), Toulouse, 2018

29. G. Mariaux, E. Legros, and A. Vardelle, Modeling of coating formation and heat flux to substrate by particles and plasma jet in plasma spraying, Thermal Spray 2003: Advancing the Science and Applying the Technology, B.R. Marple and C. Moreau, Ed., May 5-8, 2003 (Orlando, FL), ASM International, 2003, p 895-904

30. P.L. Fauchais, J.V.R. Heberlein, and M.I. Boulos, Thermal Spray Fundamentals, Springer, US, 2014

31. P. Fuzet, "Etude expérimentale de l'ablation de matériaux thermo-ablatifs sous impacts d'alumine liquide, modélisation et développement d'un moyen d'essai," Ph.D. Thesis, Université de Limoges, 2014 (in French)

32. X. Chen and E. Pfender, Effect of the Knudsen number on heat transfer to a particle immersed into a thermal plasma, Plasma Chem. Plasma Process., 1983, 3(1), p 97-113 
33. X. Chen and E. Pfender, Behavior of small particles in a thermal plasma flow, Plasma Chem. Plasma Process., 1983, 3(3), p 351366

34. S.L. Girshick and C.-P. Chiu, Kinetic nucleation theory: A new expression for the rate of homogeneous nucleation from an ideal supersaturated vapor, J. Chem. Phys., 1990, 93(2), p 1273-1277

35. G. Mauer and R. Vaßen, Conditions for nucleation and growth in the substrate boundary layer at plasma spray-physical vapor deposition (PS-PVD), Surf. Coat. Technol., 2018, 371, p 417-427

36. G.V. Samsonov and G.V. Samsonov, The Oxide Handbook, Springer, US, 1973

37. A. Stoklosa, Molar Volume, Ionic Radii in Stoichiometric and Nonstoichiometric Metal Oxides, Stoichiometry and Materials Science - When Numbers Matter, A. Innocenti, Ed., IntechOpen Ltd., 2012, p 219-244

38. M. Rösner-Kuhn, W.H. Hofmeister, G. Kuppermann, R.J. Bayuzick, and M.G. Frohberg, Investigations of the influence of oxygen on the surface tension of zirconium by the oscillating drop technique, Surf. Sci., 1999, 443(3), p 159-164
39. S.K. Friedlander, Smoke, Dust, and Haze: Fundamentals of Aerosol Dynamics, 2nd ed., Oxford University Press, 2000

40. J. Welty, C.E. Wicks, G.L. Rorrer, and R.E. Wilson, Fundamentals of Momentum, Heat and Mass Transfer, 5th ed., Wiley, 2007

41. R.L. Williamson, J.R. Fincke, and C.H. Chang, A Computational Examination of the Sources of Statistical Variance in Particle Parameters During Thermal Plasma Spraying, Plasma Chem. Plasma Process., 2000, 20(3), p 299-324

42. G. Mauer, A. Hospach, N. Zotov, and R. Vaßen, Process Conditions and Microstructures of Ceramic Coatings by Gas Phase Deposition Based on Plasma Spraying, J. Therm. Spray Technol., 2012, 22(2-3), p 83-89

Publisher's Note Springer Nature remains neutral with regard to jurisdictional claims in published maps and institutional affiliations. 